\title{
Targeted Epigenetic Remodeling of the Cdk5 Gene in Nucleus Accumbens Regulates Cocaine- and Stress-Evoked Behavior
}

\author{
타izabeth A. Heller, ${ }^{1 \star}$ Peter J. Hamilton, ${ }^{1 \star}$ Dominika D. Burek, ${ }^{1}$ @Sonia I. Lombroso, ${ }^{1}$ Catherine J. Peña, ${ }^{1}$ \\ Rachael L. Neve, ${ }^{2}$ and ${ }^{\circ}$ Eric J. Nestler ${ }^{1}$ \\ ${ }^{1}$ Fishberg Department of Neuroscience and Friedman Brain Institute, Icahn School of Medicine at Mount Sinai, New York, New York 10029, and \\ ${ }^{2} \mathrm{McG}$ overn Institute for Brain Research, Massachusetts Institute of Technology, Cambridge, Massachusetts 02139
}

Recent studies have implicated epigenetic remodeling in brain reward regions following psychostimulant or stress exposure. It has only recently become possible to target a given type of epigenetic remodeling to a single gene of interest, and to probe the functional relevance of such regulation to neuropsychiatric disease. We sought to examine the role of histone modifications at the murine Cdk5 (cyclindependent kinase 5) locus, given growing evidence of $C d k 5$ expression in nucleus accumbens (NAc) influencing reward-related behaviors. Viral-mediated delivery of engineered zinc finger proteins (ZFP) targeted histone H3 lysine 9/14 acetylation (H3K9/14ac), a transcriptionally active mark, or histone $\mathrm{H} 3$ lysine 9 dimethylation $(\mathrm{H} 3 \mathrm{~K} 9 \mathrm{me} 2)$, which is associated with transcriptional repression, specifically to the $C d k 5$ locus in NAc in vivo. We found that $C d k 5$-ZFP transcription factors are sufficient to bidirectionally regulate $C d k 5$ gene expression via enrichment of their respective histone modifications. We examined the behavioral consequences of this epigenetic remodeling and found that $C d k 5$-targeted $\mathrm{H} 3 \mathrm{~K} 9 / 14$ ac increased cocaine-induced locomotor behavior, as well as resilience to social stress. Conversely, Cdk5-targeted H3K9me2 attenuated both cocaine-induced locomotor behavior and conditioned place preference, but had no effect on stress-induced social avoidance behavior. The current study provides evidence for the causal role of $C d k 5$ epigenetic remodeling in NAc in Cdk5 gene expression and in the control of reward and stress responses. Moreover, these data are especially compelling given that previous work demonstrated opposite behavioral phenotypes compared with those reported here upon Cdk5 overexpression or knockdown, demonstrating the importance of targeted epigenetic remodeling tools for studying more subtle molecular changes that contribute to neuropsychiatric disease.

Key words: Ckd5; epigenetics; zinc finger

Significance Statement

Addiction and depression are highly heritable diseases, yet it has been difficult to identify gene sequence variations that underlie this heritability. Gene regulation via epigenetic remodeling is an additional mechanism contributing to the neurobiological basis of drug and stress exposure. In particular, epigenetic regulation of the $C d k 5$ gene alters responses to cocaine and stress in mouse and rat models. In this study, we used a novel technology, zinc-finger engineered transcription factors, to remodel histone proteins specifically at the $C d k 5$ gene. We found that this is sufficient to regulate the expression of $C d k 5$ and results in altered behavioral responses to cocaine and social stress. These data provide compelling evidence of the significance of epigenetic regulation in the neurobiological basis of reward- and stress-related neuropsychiatric disease.

\section{Introduction}

Within the context of neuropsychiatric disease, epigenetic changes, in the form of chromatin remodeling, have been found to contribute to the pathophysiology of drug addiction, as well as many forms of stress, in both animal models and human patients

Received Jan. 2, 2016; revised Feb. 17, 2016; accepted March 9, 2016.

Author contributions: E.A.H., P.J.H., and E.J.N. designed research; E.A.H., P.J.H., D.D.B., and S.I.L. performed research; R.L.N. contributed unpublished reagents/analytic tools; E.A.H., P.J.H., D.D.B., C.J.P., and E.J.N. analyzed data; E.A.H., P.J.H., and E.J.N. wrote the paper.

This work was supported by National Institute on Drug Abuse Grant R37DA008227 and National Institute of Mental Health Grant P50MH096890 to E.J.N., and by The Robin Chemers Neustein Postdoctoral Fellowship to E.A.H.

*E.A.H. and P.J.H. contributed equally to this work.
(Rogge and Wood, 2013; Peña et al., 2014; Turecki, 2014; Walker et al., 2015). These changes include the enrichment or depletion of histone modifications at specific genes across the genome in neurons of key brain reward regions. We have recently developed

The authors declare no competing financial interests.

Correspondence should be addressed to Elizabeth A. Heller, Department of Systems Pharmacology and Translational Therapeutics, Perelman School of Medicine, University of Pennsylvania, Philadelphia PA 19104. E-mail: eheller@mail.med.upenn.edu.

E.A. Heller's present address: Department of Systems Pharmacology and Translational Therapeutics, Perelman School of Medicine, University of Pennsylvania, 3400 Civic Center Boulevard, Philadelphia PA 19104.

DOI:10.1523/JNEUROSCI.0013-16.2016

Copyright $\odot 2016$ the authors $\quad 0270-6474 / 16 / 364690-08 \$ 15.00 / 0$ 
a novel approach to epigenetically modify a specific target gene, allowing us to experimentally distinguish between the mere presence of a histone modification and its causal molecular function (Heller et al., 2014).

Nearly a decade ago, we and others found genome-wide regulation of histone acetylation by chronic cocaine exposure $(\mathrm{Ku}-$ mar et al., 2005; Renthal et al., 2007), which correlates with changes in gene expression at key regulatory loci (Renthal et al., 2009; Maze et al., 2010; Kennedy et al., 2013). The induction of one such gene, $C d k 5$ (cyclin-dependent kinase 5), was found to be associated with hypomethylated histone H3 (Maze et al., 2010) and hyperacetylated histone $\mathrm{H} 3$ in nucleus accumbens (NAc) after chronic cocaine exposure by both gene-specific quantitative chromatin immunoprecipitation (ChIP; Kumar et al., 2005) and unbiased ChIP-chip array (Renthal et al., 2009). This finding was especially compelling in light of earlier evidence demonstrating a functional role for $C d k 5$ in NAc in mediating the cellular (Bibb et al., 2001; Norrholm et al., 2003), physiological (Takahashi et al., 2005), and behavioral (Benavides et al., 2007; Taylor et al., 2007; Zhong et al., 2014; Plattner et al., 2015) effects of cocaine or chronic stress within the NAc.

Cdk5 is a member of the small serine/threonine cyclindependent kinase (CDK) family, but it is unique in that it does not have a known function in cell cycle regulation and is highly expressed in the nervous system (Dhavan and Tsai, 2001). In addition to its critical role in neural development, CDK5 functions in adult synaptic physiology. It phosphorylates DARPP32 in striatal neurons to regulate dopamine signaling within the mesolimbic reward circuitry (Bibb et al., 2001). Induction of Cdk5 expression in NAc by both chronic investigator-administered (Bibb et al., 2001) or self-administered (Lu et al., 2003) cocaine in rodents, as well as increases in cocaine locomotor and place conditioning behavior by NAc infusion of CDK5 inhibitors (Bibb et al., 2001) or intra-NAc knockout of Cdk5 (Benavides et al., 2007), point to a role for $C d k 5$ in the regulation of reward pathophysiology. Furthermore, knockout of $C d k 5$ expression in dopaminergic neurons within the ventral tegmental area (VTA) or in NAc neurons increases and decreases, respectively, depressionrelated behavioral responses to stress in rodents (Zhong et al., 2014; Plattner et al., 2015). In contrast, the induction of CDK5 activity in striatum, via overexpression of the CDK5 activator p25, blunted locomotor responses to cocaine (Meyer et al., 2008).

Given the crucial role of $C d k 5$ expression in these contexts, and the known regulation of $C d k 5$-associated histone modifications by cocaine, we aimed to uncover the causal relevance of epigenetic remodeling at the Cdk5 locus in NAc in vivo. Until recently, it has not been possible to examine the functional importance of epigenetic modifications at a single gene in vivo due to the promiscuous nature of the transcriptional machinery, including histone- and DNA-modifying enzymes. Here we tested the hypothesis that histone modification of Cdk5 in NAc is sufficient to regulate its expression, and that this modification alone influences behavioral responses to drug or stress exposure. To this end, we developed a Cdk5-targeted approach, using viral delivery of engineered zinc finger protein (ZFP) transcription factors (Heller et al., 2014), to deliver a specific histone modification to $C d k 5$ in neurons within NAc in vivo. This novel genetargeted approach makes it possible to directly examine the behavioral and biochemical consequences of $C d k 5$ epigenetic remodeling in the context of cocaine and stress exposure.

\section{Materials and Methods}

Animals and treatments. Male 7- to 8-week-old C57BL/6J mice and 6 -month-old CD1 retired breeders were housed five per cage at $22-25^{\circ} \mathrm{C}$ in a $12 \mathrm{~h} \mathrm{light/dark} \mathrm{cycle,} \mathrm{and} \mathrm{were} \mathrm{provided} \mathrm{food} \mathrm{and} \mathrm{water} \mathrm{ad} \mathrm{libitum.}$ Members of the same cage were randomly assigned to different experimental groups for behavioral studies, and the order of testing was distributed across groups. Wherever possible, the experimenter conducting the data analysis was blind to treatment conditions of the animals. All experiments were conducted in accordance with the guidelines of the Institutional Animal Care and Use Committee at Mount Sinai. Group size determination was based on published protocols or on formal tests of hypothesis, as described in the Guidelines for the Care and Use of Mammals in Neuroscience and Behavioral Research (Institute for Laboratory Animal Research Committee on Guidelines for the Use of Animals in Neuroscience and Behavioral Research, 2003).

Transcription factor engineering. ZFPs were manufactured by the CompoZr ZFN Operations Group at Sigma-Aldrich and cloned in frame $\mathrm{N}$-terminal to the functional domain. The ZFPs recognize the following unique $18-20$ bp motifs in the Cdk5 promoter: ZFP1, GGCATTCTT GGGAACTAT, Chr5, 23929465-23929448; ZFP2, CCTCCTCTGCA ACGCCAG, Chr5: 23929372-23929355.

N2a transfection, RNA isolation, and quantitative RT-PCR. Neuro2a cells [CCL-131, ATCC (manufacturer authentication available on-line)] were cultured and transfected with $400 \mathrm{ng}$ of plasmid DNA using Effectene reagent (Qiagen), and RNA was isolated using the RNeasy Mini Kit (Qiagen) according to the manufacturer instructions. qPCR and data analysis were performed as described previously (Covington et al., 2011), using the following forward/reverse primers, respectively: CDK5, GCTGCCAGACTATA AGCCCTAC/TGGGGGACAGAAGTCAGAGAA; $\triangle$ FOSB, AGGCAGA GCTGGAGTCGGAGAT/GCCGAGGACTTGAACTTCACTCG; GAPDH, AGGTCGGTGTGAACGGATTTG/TGTAGACCATGTAGTTGAGGTCA; ZFP-p65, GTTCACAGACCTGGCATCCGTCG/CCCAGTGGAGCAGG AGCTGGGTC; and ZFP-G9a, CCTGCACATCGCAGCTCGGG/AGC TTGCGGTTGAGTTGAAGCG.

Data were analyzed by comparing $\mathrm{C}(\mathrm{t})$ values of the experimental construct with mock-transfected cells using the $\Delta \Delta \mathrm{C}(\mathrm{t})$ method.

Viral-mediated gene transfer and NAc isolation. Mice were anesthetized with ketamine $(100 \mathrm{mg} / \mathrm{kg})$ and xylazine $(10 \mathrm{mg} / \mathrm{kg})$, and were prepared for stereotaxic surgery. Thirty-three gauge Hamilton syringe needles were used to bilaterally infuse $1.0 \mu$ l of bicistronic p1005 herpes simplex virus (HSV) vector into NAc at a rate of $0.2 \mu \mathrm{l} / \mathrm{min}$ at $1.6 \mathrm{~mm}$ anteroposterior, $+1.5 \mathrm{~mm}$ lateral, and $4.4 \mathrm{~mm}$ dorsoventral from bregma. We used bicistronic p1005 HSV vectors expressing GFP alone or GFP plus Cdk5-ZFP. In this system, GFP expression is driven by a cytomegalovirus promoter, whereas the gene of interest is driven by the IE4/5 promoter.

NAc RNA isolation and quantitative RT-PCR. Seventy-two hours after viral infection, when transgene expression is maximal, mice were rapidly decapitated, and brains were removed and placed on ice. A fluorescence microscope (Leica) was used to visualize NAc targeting of GFPexpressing virus and to accurately dissect only infected tissue using a 1 $\mathrm{mm}$ aluminum Harris micro-punch (Sigma-Aldrich). Tissue was frozen on dry ice until RNA isolation, qPCR, and data analysis (see above).

For off-target genes the following forward/reverse primers were used: ASIC3, AGACAGAGTCCTGGGGTACT/ACTCTTCCTGGAGCAGAGT GTT; SLC4a2, CACCTTGTTGCCCTGAAAGC/GCTCTGGCGTGTG CAAAGAA; ABCB8, CACATTGGTGAGCGCATGG/GAAAGCAATGT CTTGCCGGA; FASTK, TCATCATCCGAAACTGCCCC/GGAAAGC CAAGTAACACTGCAA; TMUB1, TGACTCTGAGCAGGTAGCCA/CC TGGAAACTGGGTCCTTTTTAAG; AGBL4, CCCATGCCAAGACTTC GGAAA/TGGAGACGTTGCTGGTTGAG; HCFC2, CGATGGCTTCAA GACCAGGAA/GAAAGGCCACCCTTTCTTCAA; SRSF10, TTTGCC CGAGCCCGTTAG/AATCTTCAGACCTGGTGTCGTC; HSD17B12, GAGCCTCGTACTCGCTCTTC/CCACCTGTAACAACTGCCCA; PRDM1, GTGGACTGGGTGGACATGAG/GGGGCAGCCAAGGTC GTA; RPAP3, CGCCGTGGCGGACTT/GCGTTGTGTTTCACCTG GAG; CTNNA2, TTGTGTCAGGGCTGGACAGTG/CAGCTGCTG TTCCATAGACCT; RNF6, TAGCTTTCTCTCCGCCAGGT/TGAGA GCTGCTCATCGAGGC; GAL3ST2, TCTGGCATGCTGAGAACTGG/ 
GAAGGACCTCTGTGTGCCTC; and CELSR1, CAGGCCGTGAGC ATCTCAAT/GCCTCATGGTTTCTCTGAGTC.

Chromatin immunoprecipitation. ChIP was performed on bilateral NAc $1 \mathrm{~mm}$ punches pooled from four to five mice, as described previously (Heller et al., 2014). Chromatin was sheared using a diogenode Bioruptor XL at high sonication intensity for $30 \mathrm{~s}$ on/ $30 \mathrm{~s}$ off for $2 \times 25 \mathrm{~min}$. Fragment size was verified with an Agilent 2100 Bioanalyzer at $150-300 \mathrm{bp}$. Sheared chromatin was incubated overnight with the following antibodies previously bound to magnetic beads (Dynabeads M-280, Life Technologies): anti-H3K9me2 antibody (ab1220, Abcam; Maze et al., 2010); and H3K9/14ac (17-615, EMD Millipore; Renthal et al., 2009). After reverse cross-linking and DNA purification (Spin Column, Qiagen), enrichment of the Cdk5 promoter was determined by quantitative (q) RT-PCR using the following forward/reverse primers, respectively: CDK5-PRO1, AACACCCAACCAGGTCAGAG/ CGCGTTCCAGAATACAGTGA; CDK5-PRO2, AGGCTGTGAGCACA GAAAAGG/CACGCGGACTACAAAGTCCAA; CDK5-PRO3, CTTTGT AGTCCGCGTGTCCT/TCTCCAGTTTCTCGTATTTCTGC; and CDK5PRO4, AGTACCACCTCCTCTGCAAC/GCCGGTATAGCTGACGGTAA.

Locomotor activity and conditioned place preference. Both assays were performed per published protocols (Kelz et al., 1999). Locomotor activity was assessed in the $x$ - and $y$-planes for horizontal ambulations in 75 $\mathrm{cm}^{2}$ chambers using EthoVision XT (Noldus). On each day, mice were injected with saline and analyzed for $15 \mathrm{~min}$, then were immediately injected with cocaine (15 or $10 \mathrm{mg} / \mathrm{kg}$ ) and analyzed for $45 \mathrm{~min}$. Locomotor activity was measured $7 \mathrm{~d}$ after the last cocaine injection following a challenge cocaine injection.

For conditioned place preference (CPP), mice were placed in a threechambered CPP box for $20 \mathrm{~min}$ to assess pretest preferences. For the next $2 \mathrm{~d}$, mice were injected in both the morning (saline) and afternoon ( 7.5 or $3.75 \mathrm{mg} / \mathrm{kg}$ cocaine) and then restrained to one chamber for $30 \mathrm{~min}$. On day 3, mice were placed in the CPP box with free access to both chambers for a $20 \mathrm{~min}$ test session. Data are represented as time spent in the cocaine paired chamber-time spent in the unpaired chamber.

Social defeat and behavior testing. Mice underwent $4 \mathrm{~d}$ of accelerated social defeat stress, as described previously (Berton et al., 2006; Lobo et al., 2013). They were exposed for 4 consecutive days to a novel aggressive CD1 retired breeder for $10 \mathrm{~min}$ in a large hamster cage twice daily (A.M. and P.M.), with $5 \mathrm{~h}$ of rest between sessions. Between bouts, mice were housed separated from the aggressor by a perforated divider to maintain sensory contact. Mice were tested for social interaction $24 \mathrm{~h}$ after the last social defeat interaction, first as time spent interacting with a novel cage with no target mouse present and then with a mouse present inside the cage (Berton et al., 2006; Krishnan et al., 2007). Based on the interaction ratio, defined as time spent with target/time spent with no target, mice were characterized as susceptible $(<1)$ or resilient $(>1$; Krishnan et al., 2007). Following the social interaction test, mice were tested in a standard elevated plus maze for $10 \mathrm{~min}$, monitored by EthoVision XT and analyzed for $1 \%$ sucrose consumption in a sucrose preference test for $4 \mathrm{~d}$.

Statistics. The appropriate statistical test was determined based on the number of comparisons being performed. Student's $t$ tests were used for comparison of two groups, in the analysis of qRT-PCR, qChIP, and social interaction data. One-way ANOVA was used for the analysis of three or more experimental groups, with a Bonferroni correction test post hoc, when appropriate, in the analysis of mouse locomotor data. Main and interaction effects were considered significant at $p<0.05$. Data are expressed as the mean \pm SEM. The Grubbs test was used when appropriate to identify outliers. $F$ tests of variance were conducted on all datasets to ensure that the data followed a normal distribution. All experiments were performed one to three times, and data replication was observed in instances of repeated experiments. Experimental sample sizes, as indicated in the Results section and figure legends, were determined to give SEM values that were sufficiently low to allow meaningful interpretation of the data. For N2a RT-PCR experiments, $n$ refers to the number of individually transfected plates. In NAc RT-PCR experiments, $n$ refers to the number of animals (bilateral NAc). For NAc qChIP experiments, $n$ refers to the number of samples, each from pooling NAcs from four to five mice. For all behavioral experiments, $n$ refers to the number of mice.

\section{Results}

Previous data demonstrate that cocaine regulates histone modifications at the $C d k 5$ locus, which correlates with increased gene expression (Kumar et al., 2005; Renthal et al., 2009; Maze et al., 2010). To determine the causality of such epigenetic remodeling at this gene, we generated engineered ZFPs (Urnov et al., 2005; Minczuk et al., 2010) targeting the $C d k 5$ gene promoter at two distinct sites unique to the mouse genome (Fig. 1A). A given ZFP is composed of six zinc fingers, which together recognize an $18 \mathrm{nt}$ motif unique to the mouse genome. Each ZFP was fused to either the p65 transcriptional activation domain (Liu et al., 2001) or the pre-SET (Su(var)3-9enhancer of zeste-trithorax) and SET domains of the transcriptional repressor G9a (Snowden et al., 2003). In each case, DNA binding is conferred solely by the zinc fingers, enabling selective targeting of the functional moiety to the $C d k 5$ target gene. We compared the effects of ZFP-p65 and ZFP-G9a fusion proteins on the catalytic domain ZFP-p65 or ZFP-G9a, alone, to rule out off-target effects of the functional moieties per se.

To initially examine transcriptional activity, we first transfected N2a cells with Cdk5-ZFP1-p65 or Cdk5-ZFP2-p65. We found that Cdk5-ZFP1-p65 upregulated Cdk5 mRNA expression by 1.5 -fold relative to mock-transfected cells $\left(n=4,4 ; t_{(6)}=2.5\right.$, $p=0.046)$, while $C d k 5$-ZFP2-p65 had no effect $\left(n=4,4 ; t_{(6)}=\right.$ $0.40, p=0.702$; Fig. $1 B$ ). We next used HSV vectors for targeted ZFP delivery to mouse NAc neurons (Carlezon et al., 2000). We selected HSV because of its neuron-specific infection, its fast and robust expression profile, and its large packaging capacity. Mouse NAc was injected with HSV-Cdk5-ZFP1-p65 or the -p65 domain alone, and harvested for mRNA $72 \mathrm{~h}$ later. We found that HSVCdk5-ZFP1-p65 activates $C d k 5$ expression in vivo (Fig. $1 B$ ) relative to -p65 alone $\left(n=6,5 ; t_{(9)}=3.98, p=0.003\right)$, demonstrating the efficacy of HSV-Cdk5-ZFP1-p65.

To accomplish bidirectional regulation of $C d k 5$, we generated Cdk5-ZFP1-G9a and Cdk5-ZFP2-G9a fusion proteins. While neither construct repressed $C d k 5$ in N2a cells, we found that HSV-Cdk5-ZFP2-G9a repressed transcription of $C d k 5$ when infused into NAc, relative to the -G9a domain alone $\left(n=5,4 ; t_{(7)}=\right.$ $3.78, p=0.007$; Fig. 1C). HSV-Cdk5-ZFP1-G9a did not have a significant effect in vivo $\left(n=5,4 ; t_{(7)}=1.89, p=0.100\right)$. The discrepancy between N2a and NAc regulation of gene expression by ZFP-G9a fusions is consistent with our previous findings using ZFPs targeting a different gene, FosB (Heller et al., 2014), and further emphasizes that gene regulation observed in cultured cells is often not an accurate reflection of regulation that occurs in adult neurons in the intact brain in vivo. As well, it is noteworthy that ZFPs recognizing distinct target sites in the $C d k 5$ promoter mediate either activation or repression, suggesting a locusspecific effect in transcriptional regulation by these factors.

In designing engineered transcription factors, we selected -p65 and -G9a functional domains to recapitulate cocaine-regulated histone modifications observed in vivo (Renthal et al., 2009; Maze et al., 2010). Using a set of tiling primers across the $C d k 5$ promoter, we found that HSV-Cdk5-ZFP1-p65 increased H3K9/14ac levels relative to -p65 $\left(n=9,7 ; t_{(14)}=2.17, p=0.048\right)$ in a specific region $\sim 150$ bp upstream (us) from the transcription start site (TSS) of the $C d k 5$ gene that spanned the ZFP1 binding site (Fig. $1 D$ ). We next performed equivalent studies for HSV-Cdk5-ZFP2-G9a. G9a catalyzes the repressive histone modification, histone $\mathrm{H} 3$ lysine 9 dimethylation (H3K9me2), and both G9a and total H3K9me2 levels are repressed in NAc by repeated cocaine exposure, leading to the de-repression of hundreds of genes including Cdk5 (Maze et al., 2010). We found that HSV-Cdk5-ZFP2-G9a increased H3K9me2 
A Cdk5-ZFP1
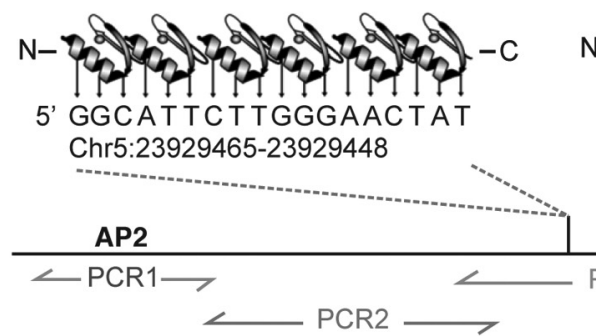

B

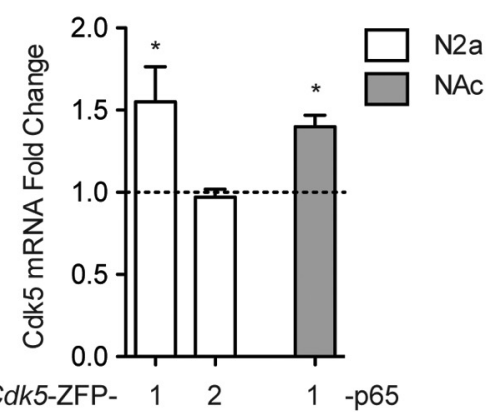

C

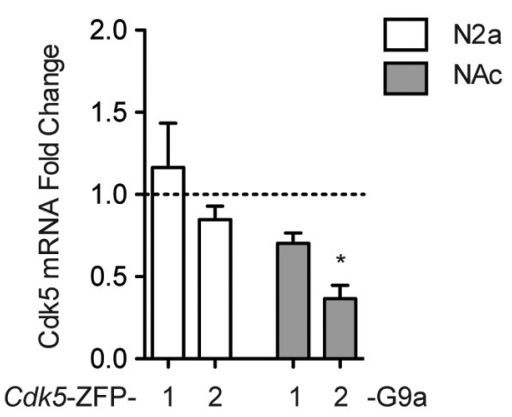

Cdk5-ZFP2

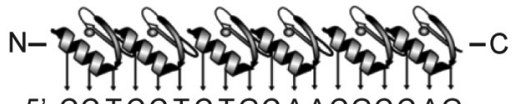

5' CCTCCTCTGCAACGCCAG Chr5:23929372-23929355

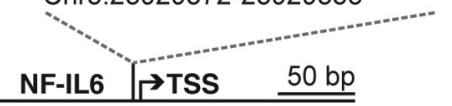

PCR3
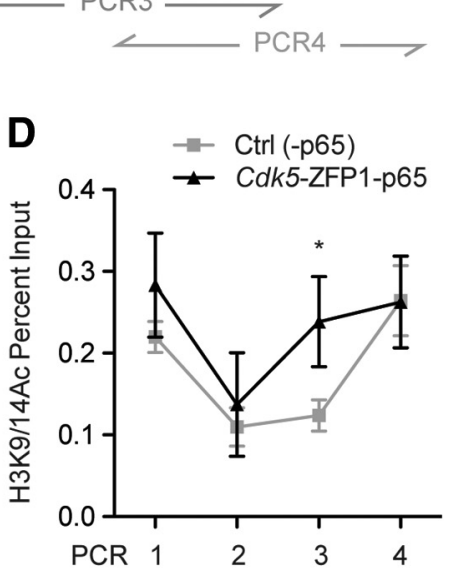

E

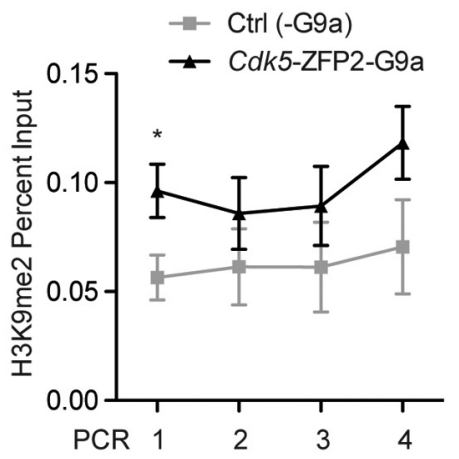

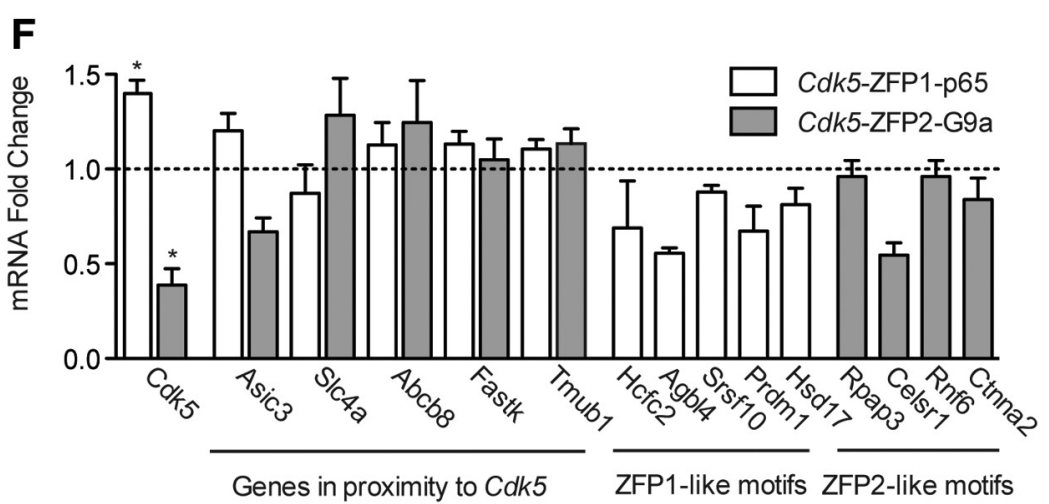

Figure 1. C C $d k 5$-ZFPs bidirectionally regulate $(d k 5$ expression and modify histones in vivo. A, Cdk5-ZFP1 and Cdk5-ZFP2 target the murine $(d k 5$ promoter at unique 18 bp recognition sites. The TSS and motifs for transcription factors NFIL6 and AP2 are also shown. $B$, qRT-PCR results show that $C d k 5$-ZFP1 fused to the transcriptional activation domain p65 increases $C d k 5$ mRNA expression when transfected into N2a cells, while Cdk5-ZFP2-p65 has no effect. N2a data are normalized to mock-transfected cells ( $n=$ $4,4,4)$. HSV-mediated delivery of (dk5-ZFP1-p65 to NAc also increases (dk5 mRNA expression in vivo. NAc data are normalized to HSV-p65, which lacks a DNA binding domain $(n=6,5)$. C, C $d k 5$-ZFP1 and Cdk5-ZFP2 fused to the transcriptional repression domain G9a have no effect on C $d k 5$ mRNA expression in transfected N2a cells $(n=4,4,4)$, while HSV-mediated delivery of C $d k 5$-ZFP2-G9a to NAc represses (dk5 expression in vivo $(n=5)$. NAc data are normalized to HSV-G9a, which lacks a DNA binding domain $(n=4)$. D, qChIP for H3K9/14ac shows that HSV-Cdk5-ZFP1-p65 enriches histone acetylation at the C dk5 promoter in NAc $(n=9,7)$ levels relative to -G9a $\left(n=5,5 ; t_{(8)}=2.48\right.$, $p=0.038)$ in a specific region $\sim 1000 \mathrm{bp}$ upstream from the Cdk5 TSS (Fig. 1E).

To verify the specificity of our ZFPtargeted approach, we analyzed the transcriptional regulation of a subset of potential off-target genes. The following five genes were selected because of their close physical proximity to the $C d k 5$ promoter at varying distances us or downstream (ds) from the Cdk5-ZFP binding region: Asic3 ( $\sim 570$ bp ds); $A b c b 8(\sim 8.3$ $\mathrm{kb} \mathrm{ds}) ;$ Slc4a2 ( $\sim 5.5 \mathrm{~kb}$ us); Fastk ( $\sim 14.8$ $\mathrm{kb}$ us); and Tmub1 ( $\sim 21.9 \mathrm{~kb}$ us). None of these genes showed regulation by the Cdk5-ZFPs when expressed in NAc (Fig. $1 F)$. An additional nine genes that contain intragenic or promoter motifs similar to the ZFP1 (five genes) or ZFP2 (four genes) target sequences, with a mismatch of 1-3 nt, also showed no regulation by the Cdk5-ZFPs (Fig. $1 F$ ).

Previous studies have found that $C d k 5$ is upregulated upon repeated cocaine administration (Bibb et al., 2001), which correlates with increased acetylation at this locus (Kumar et al., 2005; Renthal et al., 2009). Furthermore, conditional knockout of this gene leads to aberrations in cocaine-evoked behavior (Benavides et al., 2007). To determine the causal relevance of histone acetylation at the promoter region of $C d k 5$ to cocaine-evoked locomotor behavior, we injected mouse NAc with HSV-Cdk5-ZFP1p65 before investigator-administered daily cocaine treatment $(10 \mathrm{mg} / \mathrm{kg}$, i.p.; Fig. $2 A)$. We found that HSV-Cdk5-ZFP1-p65 enhanced the effects of cocaine on locomotor behavior (Fig. 2B). Repeated-measures ANOVA showed a main effect of cocaine $\left(F_{(1,36)}=71.587, p<0.001\right)$ and a main effect of virus $\left(F_{(1,36)}=7.662, p=0.009\right)$, with an interaction between cocaine and virus $\left(F_{(1,36)}=5.008, p=0.032\right)$.

We next sought to determine the role of histone methylation at the promoter region of Cdk5 in cocaine-evoked locomotor behavior. We measured cocaineinduced locomotor behavior $(15 \mathrm{mg} / \mathrm{kg}$, i.p.) starting $5 \mathrm{~d}$ after HSV-Cdk5-ZFP2G9a or HSV-G9a injection into NAc, to allow for protein turnover and to prevent basal Cdk5 levels from obscuring the effects of the ZFP repressor. Cdk5-ZFP2G9a diminished the effects of cocaine on

E, qChIP for H3K9me2 shows that HSV-Cdk5-ZFP2-G9a enriches histone methylation at the $C d k 5$ promoter in $\operatorname{NAc}(n=$ 5,5). $\boldsymbol{F}, \mathrm{qRT}-\mathrm{PCR}$ shows no regulation of putative off-target genes in NAC infected with either Cdk5-ZFP1-p65 or Cdk5ZFP2-G9a ( $n=5$ ZFP, 5 control for each gene). 
A

B
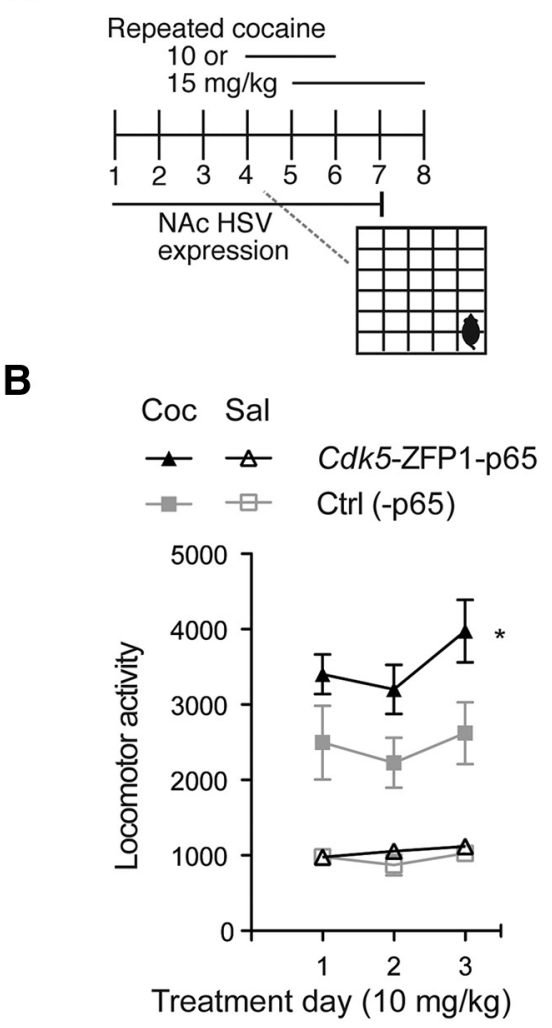

C
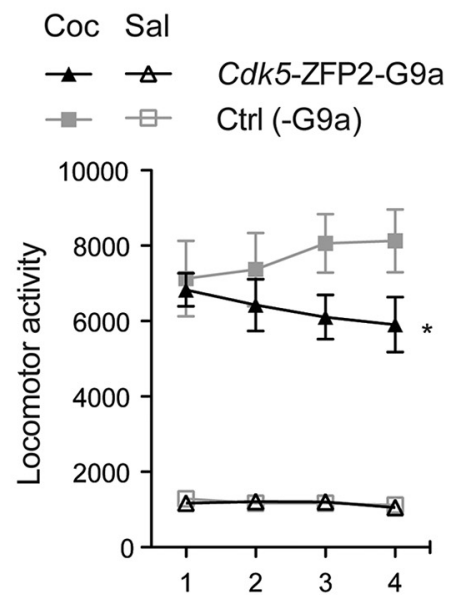

Treatment day $(15 \mathrm{mg} / \mathrm{kg})$

Figure 2. Epigenetic remodeling by Cdk5-ZFPs bidirectionally regulates cocaine (Coc) locomotor behavior. A, Mice were injected intra-NAc with HSV sexpressing Cdk5-ZFP1-p65 ( $n=10)$, Cdk5-ZFP2G9a $(n=8)$, or control (Ctrl) viruses (dk5-p65 $(n=9)$ or-G9a $(n=10)$, and were allowed to recover for $72 \mathrm{~h}$ before being subject to cocaine treatment for $4 \mathrm{~d}$, followed by $8 \mathrm{~d}$ of abstinence and a challenge dose. $\boldsymbol{B}$, At a moderate dose of cocaine (10 mg/kg, i.p.), Cdk5-ZFP1-p65 enhanced the locomotor-activating effects of cocaine over the $4 \mathrm{~d}$ course, with no difference observed after a challenge dose. C, At a higher dose of cocaine (15 mg/kg, i.p.), Cdk5-ZFP2-G9a diminished the locomotor effects of cocaine over the $4 \mathrm{~d}$ course, with no difference observed after a challenge dose. Neither virus had an effect on locomotor behavior following saline (Sal) treatment.

locomotor activity. Using a repeated-measures ANOVA, we found a significant main effect of cocaine $\left(F_{(1,32)}=162.15, p<\right.$ $0.001)$, a significant within-subject interaction effect between day and virus $\left(F_{(3,32)}=2.938, p=0.035\right.$, sphericity assumed $)$, and a significant interaction among day, virus, and cocaine $\left(F_{(3,32)}=\right.$ $3.112, p=0.030)$. Together, these data demonstrate that targeted

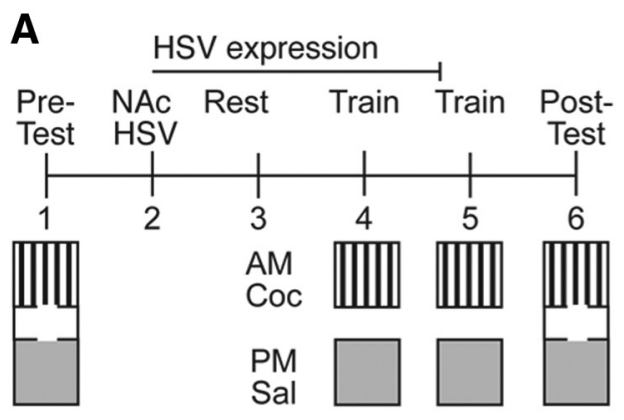

B

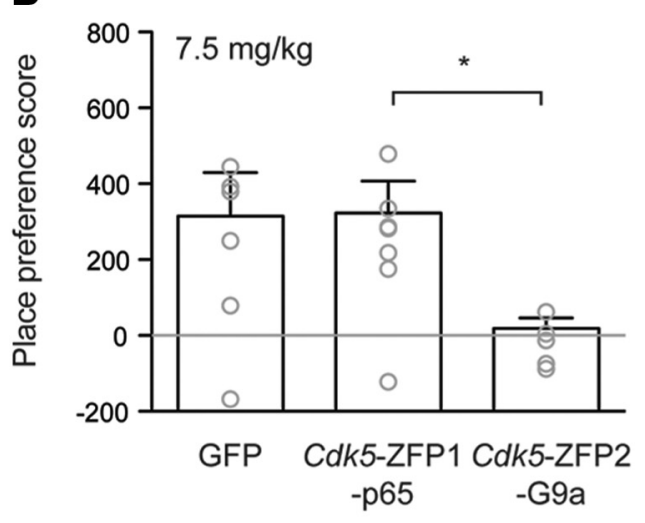

C

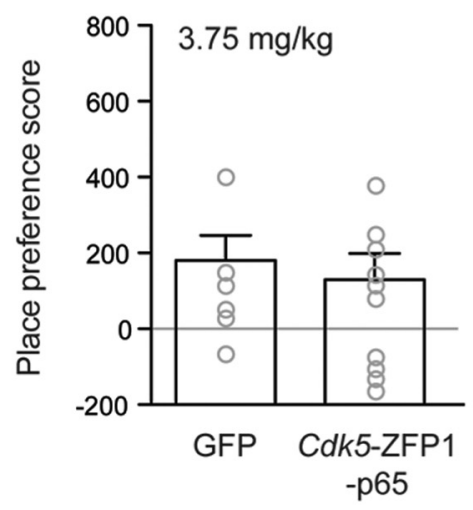

Figure 3. Epigenetic remodeling by (dk5-ZFP2-G9a represses cocaine (Coc) place conditioning. A, Mice were injected intra-NAc with HSVs expressing Cdk5-ZFP1-p65 ( $n=7)$, Cdk5-ZFP2$\mathrm{G9a}(n=6)$, or control GFP $(n=6)$, and were allowed to recover for $72 \mathrm{~h}$ before being subjected to (PP. B, At a moderate dose of cocaine ( $7.5 \mathrm{mg} / \mathrm{kg}$, i.p.), control mice formed a significant preference for the cocaine-paired chamber, which was completely blocked by the injection of HSV-Cdk5-ZFP2-G9a. Injection of HSV-Cdk5-ZFP1-p65 had no effect on cocaine preference. C, At a low dose of cocaine $(3.75 \mathrm{mg} / \mathrm{kg}$, i.p.), neither control mice nor mice injected with HSV-Cdk5ZFP1-p65 showed a preference for the cocaine-paired chamber, ruling out the possibility of a ceiling effect masking an effect of HSV-Cdk5-ZFP1-p65. Sal, Saline.

epigenetic modification at $C d k 5$ is sufficient to augment (H3K9/ $14 \mathrm{ac})$ or attenuate (H3K9me2) the locomotor effects of repeated cocaine exposure.

To investigate our hypothesis that histone modification at the promoter region of $C d k 5$ is also involved in cocaine reward and the formation of cocaine context-associated memories, mice were injected intra-NAc with HSV-Cdk5-ZFP1-p65, HSV-Cdk5-ZFP2-G9a, or HSV-GFP as a control, and were subjected to cocaine-induced CPP (Fig. 3A). Mice expressing HSV-Cdk5-ZFP2-G9a showed reduced CPP compared with mice expressing HSV-GFP at a moderate dose of cocaine 
$\left(F_{(1,18)}=20.21, p=0.035 ; 7.5 \mathrm{mg} / \mathrm{kg} ;\right.$ Fig. $\left.3 B\right)$. However, NAc injection of HSV-Cdk5-ZFP1-p65 had no effect (Fig. 3B). To rule out the possibility of a ceiling effect masking any consequences of induced acetylation at the $C d k 5$ locus, we reduced the dosage of cocaine to $3.75 \mathrm{mg} / \mathrm{kg}$. While control animals showed a reduction in CPP at this lowered cocaine dose (averaged score, <200), HSV-Cdk5-ZFP1-p65 was still insufficient to augment cocaine place preference.

Recent studies have found that, in addition to its role in reward pathology, $C d k 5$ also regulates stress-evoked behaviors (Zhong et al., 2014; Plattner et al., 2015). Furthermore, myriad studies by our group and others have identified the role of histone-modifying enzymes and global epigenetic modifications underlying many forms of stress-evoked phenotypes (Peña et al., 2014), yet no study has investigated the role of epigenetic regulation of $C d k 5$. We thus examined the causal role of $C d k 5$-associated histone modifications following social defeat stress, a model of stress-induced depression-like behavioral abnormalities in mice that is regulated in particular by NAc plasticity. We used an accelerated social defeat stress protocol, which induces defeat-related behavioral abnormalities over the time course of maximal HSV transgene expression (Fig. 4A; Krishnan et al., 2007). Mice were injected intra-NAc with HSV-Cdk5-ZFP1-p65, HSV-Cdk5-ZFP2-G9a, or control HSV-GFP. Mice were allowed to recover and then subjected to $4 \mathrm{~d}$ of social defeat stress, during which they were exposed twice daily to a 10 min physically aggressive encounter with a target CD 1 mouse, followed by $24 \mathrm{~h}$ of sensory exposure. A social interaction test following this stress paradigm examines the time that a mouse spends in an interaction zone when a caged novel CD1 mouse is present or absent. Since nonstressed mice find social interaction inherently rewarding, this test reveals social avoidance behavior specifically in stresssusceptible mice. Following social defeat stress, control mice expressing HSV-GFP exhibited the expected decreased time in the interaction zone $\left(n=9,9 ; t_{(16)}=3.00, p=0.009\right)$ and more time in the corner zones $\left(n=9,9 ; t_{(16)}=2.48, p=0.025\right)$ when the target mouse was present versus absent (Fig. $4 B, C$ ). NAc expression of HSV-Cdk5-ZFP1-p65 rescued this phenotype, indicating that histone acetylation at the Cdk5 gene in NAc is sufficient to promote a stress-resilient phenotype (Fig. $4 B, C)$. Indeed, the percentage of resilient mice was significantly greater in HSV-Cdk5-ZFP1-p65-injected mice (56\% resilient) compared with control mice $\left(11 \% ; n=9,9, \chi^{2}=\right.$ $45.45, p<0.0001)$. In contrast, the repression of $C d k 5$ via HSV-Cdk5-ZFP2-G9a had no effect; mice spent less time in the interaction zone when the target mouse was present versus absent $\left(n=10,10 ; t_{(18)}=2.13, p=0.047\right)$. We saw no significant effects of virus in sucrose preference or elevated plus maze (EPM; data not shown). Together, these data implicate certain types of epigenetic reprogramming of $C d k 5$ in promoting stress resilience.

\section{Discussion}

We present here compelling evidence that engineered transcription factors targeting the $C d k 5$ promoter are sufficient to modify histone proteins at this locus and bidirectionally regulate $C d k 5$ gene expression in vivo. This approach to targeted gene expression is unique in that it mimics experience-driven transcriptional regulation, in both magnitude (Bibb et al., 2001; Lu et al., 2003) and mechanism (Renthal et al., 2009; Maze et al., 2010). Unlike traditional overexpression or knock-out approaches, our targeted approach generates smaller changes in expression that more closely replicate gene regulation observed in vivo (Renthal et al., 2009; Feng et al., 2014).

Specifically, we show here that ZFPs targeting the $C d k 5$ locus are sufficient to activate or repress $C d k 5$ transcription when fused to either p65 or G9a, respectively. p65, a member of the nuclear factor $-\kappa \mathrm{B}$ complex, recruits histone acetyltransferases, such as CPB/p300 (Gerritsen et al., 1997) to affected promoters. We demonstrate that $C d k 5-Z F P 1-p 65$ is sufficient to enrich histone acetylation at the $C d k 5$ promoter, while the SET and pre-SET domains of the methyltransferase G9a enrich $\mathrm{H} 3 \mathrm{~K} 9 \mathrm{me} 2$ when fused to $C d k 5-Z F P 2$. Interestingly, the gene regulatory functions of Cdk5-ZFPs are locus specific; that is, only ZFP1-p65 but not ZFP2-p65 leads to gene activation, while only ZFP2-G9a but not ZFP1-G9a leads to gene repression. This functional distinction may be due to differences in the cis-regulatory landscape at each ZFP binding site or the steric availability of particular histone lysines for modification. The ZFP1 and ZFP2 motifs are located respectively at -6 and $-117 \mathrm{nt}$ from the Cdk5 TSS, which do not directly overlap with putative transcription factor binding sites, including those for SP1 ( $-51 \mathrm{nt})$, NF-IL6 ( - 332 nt), AP-1 ( - 471 nt), and AP-2 (-471 nt) (Ishizuka et al., 1995). It will be interesting in future studies to examine whether targeted histone modifications at $C d k 5$ exert their transcriptional effects via recruitment or exclusion of any of these particular factors. We have found previously that Fosb-targeted histone H3K9 methylation blocks the induction of the gene by cocaine via blocking phosphorylation of CREB bound to the Fosb promoter (Heller et al., 2014). Our approach lends itself particularly well to elucidating mechanisms such as these that operate in the intact brain.

The selection of appropriate controls was critical to our analysis of gene-targeted epigenetic remodeling. As in our previous study (Heller et al., 2014), we have relied on two classes of control constructs to rule out nonspecific function of either the ZFP or the functional moiety alone. First, we found that soluble p65 and G9a moieties, which lack cognate DNA binding and thus do not exert selective effects on $C d k 5$, had no influence on $C d k 5$ transcription. Second, to control for the possibility that ZFPs function via steric interference with endogenous transcription factor binding, we assayed the effect of a single ZFP fused to two distinct functional moieties. Given that ZFP1-G9a did not recapitulate the gene activation properties of ZFP1-p65, and that ZFP2-G9a, but not ZFP2-p65, repressed gene expression, we can rule out the possibility that gene regulation occurs by ZFP interference with promoter elements. Finally, we analyzed the expression of putative off-target loci of $C d k 5$-ZFPs and did not find any nonspecific regulation. Together, these control data verify the specificity and efficacy of $C d k 5$-ZFPs in mediating epigenetic remodeling at this locus.

The approach to functional neuroepigenetics that we take here allowed us to recapitulate the natural phenomenon of cocaine-mediated activation of $C d k 5$ expression by modeling a gene regulatory process that occurs in vivo; that is, acetylation of $C d k 5$-associated histones. This subtle manipulation resulted in a significant $(\sim 40 \%)$ increase in $C d k 5$ expression in the NAc. Accordingly, one previous study (Bibb et al., 2001) found that longterm cocaine treatment or transgenic overexpression of $\Delta \mathrm{FosB}$, a cocaine-induced transcription factor that controls C $d k 5$ expression, both lead to an $\sim 50 \%$ increase in Cdk5 mRNA levels in this brain region. While pharmacological inhibition of CDK5 has been shown previously to potentiate cocaine-induced locomotor behavior, we show here that epigenetic regulation of the endogenous $C d k 5$ gene produces the opposite effects: more subtle induction of $C d k 5$ transcription via histone acetylation increases 
A
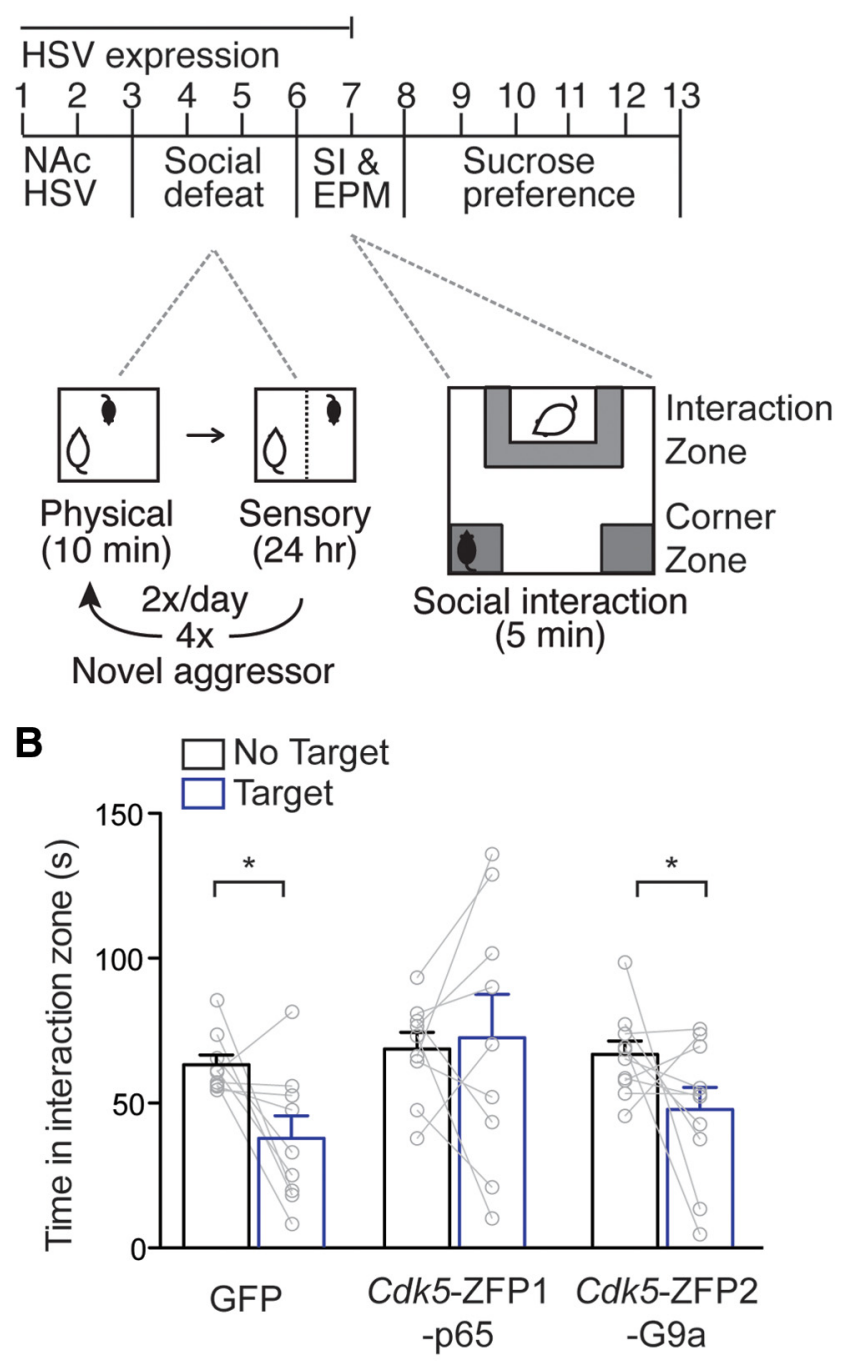

C

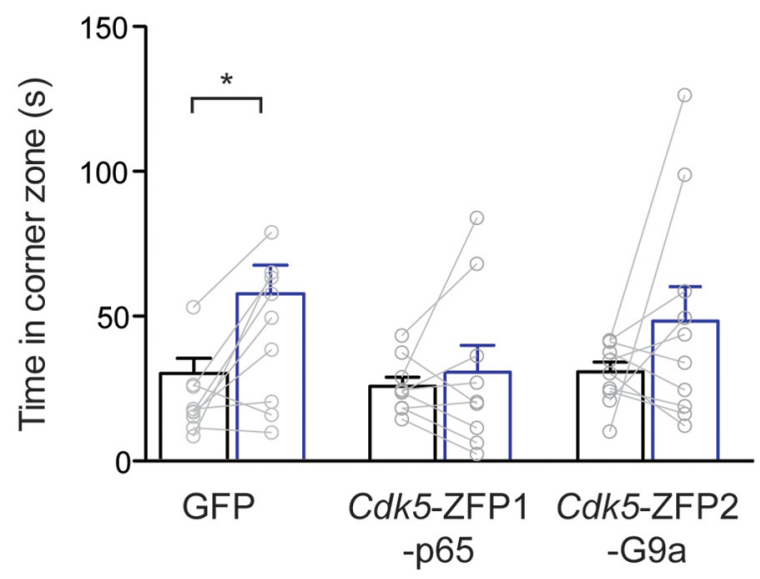

Figure 4. Epigenetic remodeling by (dk5-ZFP1-p65 promotes resilience to social defeat stress. $\boldsymbol{A}$, Mice were injected intra-NAc with HSVs expressing Cdk5-ZFP1-p65 $(n=9), C d k 5$ ZFP2-G9a $(n=10)$, or control GFP $(n=9)$, and allowed to recover for $48 \mathrm{~h}$ before being subject to an accelerated social-defeat paradigm. Following $4 \mathrm{~d}$ of social defeat stress, mice were examined in a social interaction (SI) test, as well as EPM and sucrose preference tests. $\boldsymbol{B}, \boldsymbol{C}$, Social interaction tests revealed that control mice subjected to accelerated social defeat spent $25 \%$ less time in the interaction zone $(\boldsymbol{B})$ and $28 \%$ more time in the corner zone $(\boldsymbol{C})$ when a novel mouse was present, indicating a stress-susceptible phenotype, while mice injected with behavioral responses to cocaine, while subtle suppression of $C d k 5$ transcription via histone methylation decreases behavioral responses to cocaine. This is interesting in light of an earlier paradoxical finding that NAc infusion of CDK5 inhibitors attenuates cocaine-induced increases in the dendritic spine density of NAc medium spiny neurons (Norrholm et al., 2003). These opposite behavioral results likely reflect differences in the two forms of manipulation used. Such differences include the nature of the substrate (DNA vs protein), the cellular site of action (nucleus vs cytoplasm), and the physiological relevance (endogenous histone modification vs synthetic chemical inhibition).

An alternative experimental approach used in previous studies relied on striatal overexpression of the Cdk5 coactivator p25, which blocked cocaine locomotor sensitization (Meyer et al., 2008). However, this result lacks specificity, in that $\mathrm{p} 25$ regulates several other substrates relevant to brain function, including, but not limited to, CaMKII $\alpha$ (Dhavan et al., 2002). In addition, while the effects of p25 overexpression and Cdk5 pharmacological inhibition converge with respect to their influence on cocaine locomotor responses, they diverge with respect to dendritic spine density, further indicating that the role of p25 is separable from that of Cdk5 (Norrholm et al., 2003; Meyer et al., 2008). Our study limited analysis to the effect of chromatin remodeling at $C d k 5$, and thus provides specific insight into the causal relevance of this particular manipulation on cocaine-induced behavior.

We also report the effect of histone methylation at the $C d k 5$ locus. While no prior study has directly repressed the transcription of the Cdk5 gene using, for example, RNA interference, several have used conditional knockout approaches to examine the necessity of Cdk5 in cocaine- and stress-mediated behavior. One previous study (Benavides et al., 2007) showed that CamKII-Cre/ fCdk5 conditional knock-out mice exhibit enhanced behavioral responses to cocaine, yet we find that Cdk5-ZFP2-G9a, which represses $C d k 5$ gene expression, attenuated cocaine-induced locomotor activity and CPP. Intriguingly, both the Cdk5 conditional knockout and the expression of Cdk5-ZFP-G9a lead to an $\sim 50 \%$ reduction in $C d k 5$ mRNA expression, indicating that the confounding results cannot be due to differences in Cdk5 expression levels. Rather, the different phenotypes may be explained by the brain area affected, given that we specifically targeted NAc, and that the conditional knock-out mice display significant $C d k 5$ mRNA reductions in cortex, hippocampus, and whole striatum (Benavides et al., 2007). Furthermore, local knockout of Cdk5 expression from VTA or NAc neurons increases and decreases, respectively, depression-related behavioral responses to stress in rodents (Zhong et al., 2014; Plattner et al., 2015). We find that epigenetic regulation of $C d k 5$ produced the opposite effect in NAc; subtle induction of $C d k 5$ in NAc was proresilient in a model of social defeat stress. Our hypothesis is that the nature and degree of regulation of $C d k 5$ is a key determinant of its behavioral effects, although further work is needed to study this and alternative possibilities.

In conclusion, we find that targeted epigenetic remodeling of the $C d k 5$ gene is sufficient to regulate its expression and behavioral effects in vivo. Our results demonstrate the general applicability of our targeting approach and shed new light on the subtleties of gene-targeted epigenetic remodeling underlying reward and stress pathophysiology.

HSV-Cdk5-ZFP1-p65 did not show this social avoidance, indicating stress resilience. Mice injected with HSV-Cdk5-ZFP2-G9a behaved similarly to control mice, spending 19\% less time in the interaction zone and $18 \%$ more time in the corner zone when a novel mouse was present. 


\section{References}

Benavides DR, Quinn JJ, Zhong P, Hawasli AH, DiLeone RJ, Kansy JW, Olausson P, Yan Z, Taylor JR, Bibb JA (2007) Cdk5 modulates cocaine reward, motivation, and striatal neuron excitability. J Neurosci 27:1296712976. CrossRef Medline

Berton O, McClung CA, Dileone RJ, Krishnan V, Renthal W, Russo SJ, Graham D, Tsankova NM, Bolanos CA, Rios M, Monteggia LM, Self DW, Nestler EJ (2006) Essential role of BDNF in the mesolimbic dopamine pathway in social defeat stress. Science 311:864-868. CrossRef Medline

Bibb JA, Chen J, Taylor JR, Svenningsson P, Nishi A, Snyder GL, Yan Z, Sagawa ZK, Ouimet CC, Nairn AC, Nestler EJ, Greengard P (2001) Effects of chronic exposure to cocaine are regulated by the neuronal protein Cdk5. Nature 410:376-380. CrossRef Medline

Carlezon WA Jr, Nestler EJ, Neve RL (2000) Viral-mediated gene transfer as a tool for neuropsychiatric research. Crit Rev Neurobiol 14:47-67. Medline

Covington HE 3rd, Maze I, Sun H, Bomze HM, DeMaio KD, Wu EY, Dietz DM, Lobo MK, Ghose S, Mouzon E, Neve RL, Tamminga CA, Nestler EJ (2011) A role for repressive histone methylation in cocaine-induced vulnerability to stress. Neuron 71:656-670. CrossRef Medline

Dhavan R, Tsai LH (2001) A decade of CDK5. Nat Rev Mol Cell Biol 2: 749-759. CrossRef Medline

Dhavan R, Greer PL, Morabito MA, Orlando LR, Tsai LH (2002) The cyclin-dependent kinase 5 activators p 35 and p 39 interact with the alphasubunit of $\mathrm{Ca}^{2+} /$ calmodulin-dependent protein kinase II and alphaactinin-1 in a calcium-dependent manner. J Neurosci 22:7879-7891. Medline

Feng J, Wilkinson M, Liu X, Purushothaman I, Ferguson D, Vialou V, Maze I, Shao N, Kennedy P, Koo J, Dias C, Laitman B, Stockman V, LaPlant Q, Cahill ME, Nestler EJ, Shen L (2014) Chronic cocaine-regulated epigenomic changes in mouse nucleus accumbens. Genome Biol 15:R65. CrossRef Medline

Gerritsen ME, Williams AJ, Neish AS, Moore S, Shi Y, Collins T (1997) CREB-binding protein/p300 are transcriptional coactivators of p65. Proc Natl Acad Sci U S A 94:2927-2932. CrossRef Medline

Heller EA, Cates HM, Peña CJ, Sun H, Shao N, Feng J, Golden SA, Herman JP, Walsh JJ, Mazei-Robison M, Ferguson D, Knight S, Gerber MA, Nievera C, Han MH, Russo SJ, Tamminga CS, Neve RL, Shen L, Zhang HS, et al (2014) Locus-specific epigenetic remodeling controls addiction- and depressionrelated behaviors. Nat Neurosci 17:1720-1727. CrossRef Medline

Institute for Laboratory Animal Research Committee on Guidelines for the Use of Animals in Neuroscience and Behavioral Research (2003) Guidelines for the Care and Use of Mammals in Neuroscience and Behavioral Research. Washington, DC: National Academies.

Ishizuka T, Ino H, Sawa K, Suzuki N, Tatibana M (1995) Promoter region of the mouse cyclin-dependent kinase 5-encoding gene. Gene 166:267-271. CrossRef Medline

Kelz MB, Chen J, Carlezon WA Jr, Whisler K, Gilden L, Beckmann AM, Steffen C, Zhang YJ, Marotti L, Self DW, Tkatch T, Baranauskas G, Surmeier DJ, Neve RL, Duman RS, Picciotto MR, Nestler EJ (1999) Expression of the transcription factor deltaFosB in the brain controls sensitivity to cocaine. Nature 401:272-276. CrossRef Medline

Kennedy PJ, Feng J, Robison AJ, Maze I, Badimon A, Mouzon E, Chaudhury D, Damez-Werno DM, Haggarty SJ, Han MH, Bassel-Duby R, Olson EN, Nestler EJ (2013) Class I HDAC inhibition blocks cocaine-induced plasticity by targeted changes in histone methylation. Nat Neurosci 16 : 434-440. CrossRef Medline

Krishnan V, Han MH, Graham DL, Berton O, Renthal W, Russo SJ, Laplant Q, Graham A, Lutter M, Lagace DC, Ghose S, Reister R, Tannous P, Green TA, Neve RL, Chakravarty S, Kumar A, Eisch AJ, Self DW, Lee FS, et al. (2007) Molecular adaptations underlying susceptibility and resistance to social defeat in brain reward regions. Cell 131:391-404. CrossRef Medline

Kumar A, Choi KH, Renthal W, Tsankova NM, Theobald DE, Truong HT, Russo SJ, Laplant Q, Sasaki TS, Whistler KN, Neve RL, Self DW, Nestler EJ (2005a) Chromatin remodeling is a key mechanism underlying cocaineinduced plasticity in striatum. Neuron 48:303-314. CrossRef Medline

Liu PQ, Rebar EJ, Zhang L, Liu Q, Jamieson AC, Liang Y, Qi H, Li PX, Chen B, Mendel MC, Zhong X, Lee YL, Eisenberg SP, Spratt SK, Case CC, Wolffe AP (2001) Regulation of an endogenous locus using a panel of designed zinc finger proteins targeted to accessible chromatin regions. Activation of vascular endothelial growth factor A. J Biol Chem 276: 11323-11334. CrossRef Medline

Lobo MK, Zaman S, Damez-Werno DM, Koo JW, Bagot RC, DiNieri JA,
Nugent A, Finkel E, Chaudhury D, Chandra R, Riberio E, Rabkin J, Mouzon E, Cachope R, Cheer JF, Han MH, Dietz DM, Self DW, Hurd YL, Vialou $\mathrm{V}$, et al (2013) $\Delta$ FosB induction in striatal medium spiny neuron subtypes in response to chronic pharmacological, emotional, and optogenetic stimuli. J Neurosci 33:18381-18395. CrossRef Medline

Lu L, Grimm JW, Shaham Y, Hope BT (2003) Molecular neuroadaptations in the accumbens and ventral tegmental area during the first 90 days of forced abstinence from cocaine self-administration in rats. J Neurochem 85:1604-1613. CrossRef Medline

Maze I, Covington HE 3rd, Dietz DM, LaPlant Q, Renthal W, Russo SJ, Mechanic M, Mouzon E, Neve RL, Haggarty SJ, Ren Y, Sampath SC, Hurd YL, Greengard P, Tarakhovsky A, Schaefer A, Nestler EJ (2010) Essential role of the histone methyltransferase G9a in cocaine-induced plasticity. Science 327:213-216. CrossRef Medline

Meyer DA, Richer E, Benkovic SA, Hayashi K, Kansy JW, Hale CF, Moy LY, Kim Y, O'Callaghan JP, Tsai LH, Greengard P, Nairn AC, Cowan CW, Miller DB, Antich P, Bibb JA (2008) Striatal dysregulation of Cdk5 alters locomotor responses to cocaine, motor learning, and dendritic morphology. Proc Natl Acad Sci U S A 105:18561-18566. CrossRef Medline

Minczuk M, Kolasinska-Zwierz P, Murphy MP, Papworth MA (2010) Construction and testing of engineered zinc-finger proteins for sequence-specific modification of mtDNA. Nat Protoc 5:342-356. CrossRef Medline

Norrholm SD, Bibb JA, Nestler EJ, Ouimet CC, Taylor JR, Greengard P (2003) Cocaine-induced proliferation of dendritic spines in nucleus accumbens is dependent on the activity of cyclin-dependent kinase-5. Neuroscience 116:19-22. CrossRef Medline

Peña CJ, Bagot RC, Labonté B, Nestler EJ (2014) Epigenetic signaling in psychiatric disorders. J Mol Biol 426:3389-3412 CrossRef Medline

Plattner F, Hayashi K, Hernández A, Benavides DR, Tassin TC, Tan C, Day J, Fina MW, Yuen EY, Yan Z, Goldberg MS, Nairn AC, Greengard P, Nestler EJ, Taussig R, Nishi A, Houslay MD, Bibb JA (2015) The role of ventral striatal cAMP signaling in stress-induced behaviors. Nat Neurosci 18: 1094-1100. CrossRef Medline

Renthal W, Maze I, Krishnan V, Covington HE 3rd, Xiao G, Kumar A, Russo SJ, Graham A, Tsankova N, Kippin TE, Kerstetter KA, Neve RL, Haggarty SJ, McKinsey TA, Bassel-Duby R, Olson EN, Nestler EJ (2007) Histone deacetylase 5 epigenetically controls behavioral adaptations to chronic emotional stimuli. Neuron 56:517-529. CrossRef Medline

Renthal W, Kumar A, Xiao G, Wilkinson M, Covington HE 3rd, Maze I, Sikder D, Robison AJ, LaPlant Q, Dietz DM, Russo SJ, Vialou V, Chakravarty S, Kodadek TJ, Stack A, Kabbaj M, Nestler EJ (2009) Genomewide analysis of chromatin regulation by cocaine reveals a role for sirtuins. Neuron 62:335-348. CrossRef Medline

Rogge GA, Wood MA (2013) The role of histone acetylation in cocaineinduced neural plasticity and behavior. Neuropsychopharmacology 38: 94-110. CrossRef Medline

Snowden AW, Zhang L, Urnov F, Dent C, Jouvenot Y, Zhong X, Rebar EJ, Jamieson AC, Zhang HS, Tan S, Case CC, Pabo CO, Wolffe AP, Gregory PD (2003) Repression of vascular endothelial growth factor A in glioblastoma cells using engineered zinc finger transcription factors. Cancer Res 63:8968-8976. Medline

Takahashi S, Ohshima T, Cho A, Sreenath T, Iadarola MJ, Pant HC, Kim Y, Nairn AC, Brady RO, Greengard P, Kulkarni AB (2005) Increased activity of cyclin-dependent kinase 5 leads to attenuation of cocaine-mediated dopamine signaling. Proc Natl Acad Sci U S A 102:1737-1742. CrossRef Medline

Taylor JR, Lynch WJ, Sanchez H, Olausson P, Nestler EJ, Bibb JA (2007) Inhibition of Cdk5 in the nucleus accumbens enhances the locomotoractivating and incentive-motivational effects of cocaine. Proc Natl Acad Sci U S A 104:4147-4152. CrossRef Medline

Turecki G (2014) The molecular bases of the suicidal brain. Nat Rev Neurosci 15:802-816. CrossRef Medline

Urnov FD, Miller JC, Lee YL, Beausejour CM, Rock JM, Augustus S, Jamieson AC, Porteus MH, Gregory PD, Holmes MC (2005) Highly efficient endogenous human gene correction using designed zinc-finger nucleases. Nature 435:646-651. CrossRef Medline

Walker DM, Cates HM, Heller EA, Nestler EJ (2015) Regulation of chromatin states by drugs of abuse. Curr Opin Neurobiol 30:112-121. CrossRef Medline

Zhong P, Liu X, Zhang Z, Hu Y, Liu SJ, Lezama-Ruiz M, Joksimovic M, Liu QS (2014) Cyclin-dependent kinase 5 in the ventral tegmental area regulates depression-related behaviors. J Neurosci 34:6352-6366. CrossRef Medline 